University of Wollongong

Research Online

Faculty of Engineering and Information

Faculty of Engineering and Information

Sciences - Papers: Part A

Sciences

$1-1-2016$

The social phenomenon of body-modifying in a world of technological change: past, present, future

Sharon Bradley-Munn

University of Wollongong, srbm802@uowmail.edu.au

Katina Michael

University of Wollongong, katina@uow.edu.au

M G. Michael

University of Wollongong, mgm@uow.edu.au

Follow this and additional works at: https://ro.uow.edu.au/eispapers

Part of the Engineering Commons, and the Science and Technology Studies Commons

Research Online is the open access institutional repository for the University of Wollongong. For further information contact the UOW Library: research-pubs@uow.edu.au 


\title{
The social phenomenon of body-modifying in a world of technological change: past, present, future
}

\begin{abstract}
The current level of uncritical adoption in bodymodifying devices, and the propensity for remaking the human body through the aid of technology, is moving society closer to a human-machine fusion. We are at the brink of postmodernity in all its fullness. This paper speculates on the pros and cons of such a reality and insists on the right of the individual to be able to self-govern his/her own body, maintaining the right to choose. How individual choice is limited is also discussed, as industry innovation cycles get faster, and the need for continuous disruption means that the consumer is often at the mercy of an adapt or die kind of dilemma. What happens when complex technologies, like embedded microchips become a default way of living and working, transacting and interacting with no alternatives? These are just some of the questions explored in this qualitative study on body-modifying devices.
\end{abstract}

\section{Keywords}

technological, world, social, phenomenon, body, future, modifying, present, past, change

\section{Disciplines}

Engineering | Science and Technology Studies

\section{Publication Details}

Bradley-Munn, S., Michael, K. \& Michael, M. G. (2016). The social phenomenon of body-modifying in a world of technological change: past, present, future. 2016 IEEE Conference on Norbert Wiener in the 21st Century (21CW) (pp. 72-77). United States: IEEE. 


\section{The Social Phenomenon of Body-Modifying in a World of Technological Change: Past, Present, Future}

\author{
Sharon R. Bradley-Munn \\ School of Computing \& IT \\ University of Wollongong \\ NSW, Australia \\ srbm802@uowmail.edu.au
}

\author{
Katina Michael SMIEEE \\ School of Computing \& IT \\ University of Wollongong \\ NSW, Australia \\ katina@uow.edu.au
}

\author{
MG Michael \\ School of Computing \& IT \\ University of Wollongong \\ NSW, Australia \\ mgm@uow.edu.au
}

\begin{abstract}
The current level of uncritical adoption in bodymodifying devices, and the propensity for remaking the human body through the aid of technology, is moving society closer to a human-machine fusion. We are at the brink of postmodernity in all its fullness. This paper speculates on the pros and cons of such a reality and insists on the right of the individual to be able to self-govern his/her own body, maintaining the right to choose. How individual choice is limited is also discussed as industry innovation cycles get faster, and the need for continuous disruption means that the consumer is often at the mercy of an adapt or die kind of thinking. What happens when complex technologies, like embedded microchips become a default way of living and working, transacting and interacting with no alternatives? These are just some of the questions explored in this qualitative study on body-modifying devices.
\end{abstract}

Keywords-embedded systems, body-modification, human, implants, technological change, innovation

\section{INTRODUCTION}

Tattooing and piercings date back in civilization to as early as 5000 years ago [1], p. 366. Ötzi, who was referred to as the ice man was found in 1991. His 5,200 year old frozen body featured fifty-seven tattoos and scientists suggest the way in which the body was marked was a result of therapeutic reasons [2]. Although body tattooing is not a new phenomenon, the fixation on the presentation of the body is rapidly growing in popularity to the degree that it is being situated historically as a late-modern cultural marker [2]. Social scientists believe we have reached a period where the individual has lost traditional shared meaning. This in turn is propelling a need for individuals to rework their personal identity through body modifications. These modifications take a variety of forms, including tattooing, scarification, piercing, cosmetic work (e.g. orthodontics, breast implants), and other surgeries. Typically, it is the process whereby an individual oversees the design of their own body [3], p. 305.

Chris Shilling argues that within the Western culture there is a tendency to view the body as an ongoing project that is evolving. He writes p. 309 [4]:
"In the affluent West there is a tendency for the body to be seen as an entity which is in the process of becoming; a project which should be worked at and accomplished as part of an individual's self-identity."

Body alterations are ever evolving into a multiplicity of diverse forms and are employing greater and greater uses of various technologies. The remaking of one's human body is rapidly shaping up to be one of the greatest indicators that late modernity has come to a close and post-modernity has actually arrived. This brand new historical epoch is not merely represented by a remaking of the body, but a remaking of human identity, whereby redefining what it means to be human.

\section{Defining Sub-Cultures And AVOIDING "Othering"}

Regardless of the way in which body-modifying movements are historically situated or socially contextualized, it is important to avoid participating in what is termed as "othering". "Othering" involves the "[p]rojection of racial, cultural, and [other] judgments onto a social group not of one's own, as a way to define and secure one's own positive identity through the stigmatization of an 'other"' [3] ,p. 305. When one is able to group another categorically within a fixed paradigmatic frame of reference, it provides the analyzers with a feeling of superiority over the other. With the ongoing movement concerning body modifications, theorists are concerned that there will be an over generalization [5], p. 309. For example, should the behavior of those that are "othered" be deemed as inflicting unnecessary bodily harm, even to oneself, such a generalization might lead the public to accept a top-down approach of enforcing laws to control such behavior while inadvertently removing the individual's rights to self-govern. This does not mean that we do not attend to medical and psychological behaviors, for example, individuals who are suffering from the compulsive behavior to cut themselves incessantly, but that we can separate individuals who require medical attention from those who do not.

According to Anthony Giddens, "[1]ate modernity has dissolved most traditional systems of meaning and social order in an unprecedented fashion," and this sentiment is 
reflected by an unparalleled "[i]ndividualization of the body" [5], p. 309. Giddens sees this phenomenon, in part, as a turning away from one's true nature, where an individual chooses to redefine themselves by adopting the practices of a subculture that diverts one's attention from seeking after the authentic self. We can postulate that the more the embodied self, pushes the parameters of self-autonomy and rights to alter one's physical body through unconventional and unrestrained practices, various lines of distinction are blurred. It is becoming increasingly difficult to distinguish between practices adopted by the cybernetics movement versus a top-down movement that takes ownership over the human body. We can see this battle for control over the body itself, for example, when employees are refused work based on non-concealable body art.

In addition to changing one's physical appearance through the aid of technology, by adding body-decor, external piercing, tattooing, cosmetic surgery, cutting or lacerating, microchip implants are now playing a pivotal role in the remaking of one's new identity through skinembedded devices. This movement has at times been referred to as chipification [6]. Persons who hold to these forms of adaptation and extension are often known as RFIDs, DIY-ers, body modifiers and grinders, among other things. Public resistance is noted as one factor limiting the alteration of one's own body [7]. Yet, while some look upon the chipification movement in a negative light, others are more receptive in so much that modifications to one's human appearance through the use of technology can be argued as a growing global phenomenon. Rapid and radical technological innovation is not just increasing the ways in which body alterations can be made but renders public acceptance and uncritical adoption of extreme forms of body-modification, even, for example, various forms of sadomasochism [3]. This kind of uncritical acceptance of unconventional tools and techniques continues to fuel development in subdermal humancentric implants [8].

\section{KEY PROCESSES}

\section{A. Informed Consent}

While the semiconductor industry's focus is on profit and sales maximization - innovation, marketing, and promotion of products - other stakeholders are concerned about various ethical implications, such as, where this practice could lead if soft-coercion subtlety enters into the context of technology implementation and adoption. When the VeriChip company was in operation, a single adverse event report was submitted to the Food and Drug Administration on July 27, 2007 pertaining to the removal of the administered chip, after the bearer experienced discomfort at the point of implantation some hours after the initial insertion [9]. Yet, there was no official process of removal documented by the VeriChip Corporation. This is in line with comments from the IT Manager of the Baja Beach Club in Barcelona who stated that even though the VIP Patron program had been discontinued, there were still about 100 patrons who were walking around with defunct embedded VeriChips [10].
In a basic thought experiment we can ponder the consequences of a commercial or government entity offering an embedded healthcare microchip solution that guided patients toward adoption without recourse for removal. Consider what such an implementation might mean for highrisk patients, if the only way of accessing their health-records was by accepting bio-devices, and what it would mean for no alternative mechanism to be granted. Or if at a critical moment the bio-device failed to work. This leads to the important question of an acceptable level of knowledge that would allow for informed user (e.g. patient) consent [11]. For example, does it suffice for the doctor or intake worker to inform the user of the procedure alone? Is it enough for those administering the device to advise the patient of its immediate impact, such as the fact that they will feel a small prick from the needle as the RFID is being inserted, or prior to obtaining consent, will the patient be advised of their rights to refuse, while being informed of appropriate alternatives? Another concern is whether the patient's uncritical adoption and willingness to consent can be linked to a fear of being refused equivalent levels of medical attention; if so, could this be considered a type of undue stimuli which is currently illegal? Another question to consider is, who will be providing the appropriate information needed to the patient in order for them to make a well-rounded decision? Will these individuals be true nonpartisans or will they softly-coerce toward user adoption?

Although informed consent typically refers to obtaining one's permission, while providing the user with the autonomy to choose in conjunction to respecting the individual's dignity and rights, informed consent must also involve a higher level of articulation while educating the consumer, user, or patient of all potential harms [12]. Duty of care requires the user to be kept out of harm's way. The four main reasons the public, consumer, or patient must be given the option to engage in high levels of discourse, prior to consenting, rests on various premises, including:

1. Such technology has a wireless radio-frequency component and whether embedded in the skin or used externally, is being argued as potentially altering one's physical being on a bio-cellular level, which then involves self-jurisdiction over one's body.

2. Given bio-devices or wireless device ambiances employ a constancy (regardless of the purpose of its utility) and therefore its panoptic-presence has the ability to negatively influence human well-being by turning the human psyche from without-within [13].

3. Because the debate, concerning body-altering devices, deal with changes to one's own physical being, it extends beyond mere preference to issues which involve a higher good-being moral freedom [14].

4. As this paper deals with the concept of top-down body-intrusion, it automatically evokes a need to look at the current laws of self-governance and protection, and even more so in instances where coercion is involved [15]. Imperative questions such as these are spurring the need for in-depth philosophical interpretation of state Constitutions, pertaining to the rights of self-autonomy, liberty, and 
freedom, in order to safe-guard prior to any potential crises [16].

\section{B. Duty of Care}

In order to disambiguate past laws, and rightfully take into consideration whether human rights are presently fully protected if a person adopts a microchip implant, we have to turn our attention to such areas such as duty of care in conducting patient research. So who then is responsible to ensure duty of care? For example, when it comes to using technology to test research subjects?

We need to ask as to whether bio-devices are being used in pilot studies with the prospect of top-down implementation, and if so, whether such are being deemed as viable clinical research [17]. Currently the duty of care resides between the clinician and attending physician as to decide as to whether potential risks to the patient "and/or" participant are justified. For example, currently such studies are deemed justifiable when the possible benefits override potential harm. And yet, full disclosure of potential harms are not always known or provided to the patient. It can be safely argued that although the patient appears protected under the banner of informed consent (as in the case with clinical trials), currently duty of care resides with the medical professionals and does not require full in-depth informed consent of the patients, as long as the good outweighs the risk. In this aspect, action or intent is more important than the consequences, which may certainly be the case, except the researcher of this paper argues, full informed consent is first required, disclosing all potential risks and harms and then at that point, it is up to the patient, potential user, or research participant to decide. This is just one gap found within the Tri-council policy statement which deals with ethical conduct for research involving humans [18].

\section{PROS AND CONS OF SUBDERMAL IMPLANTS}

\section{A. Pros}

In general, marketing strategies are capitalizing on the sub-dermal device's purported functional abilities to counteract fearful situations [15]. Examples include:

- Voluntary adoption could be awarded with financial incentives which could evoke a leveling of society that would (not take away from the rich) but would bring the minimum threshold of subsistence up to an equitable standard.

- Provision of rapid transmittal of medical records for high risk patients and save more lives.

- $\quad$ Stop persons from going missing, i.e., the protection of children from being kidnapped or adults from being abducted as the embedded device would disclose a person's identity in any location that there is a radiofrequency identification (RFID) reader, nearby. Although such technology is argued to only be compatible in short-range proximity, readers could be stationed in strategic locations such as automobile re-fueling stations, supermarkets, airports, highway tolling stations, acting as entry/exit gantries.

- Internalized radio frequency identification tags that would alleviate identity theft.

- The promotion of a cashless society that would then prohibit illegal transaction activity, such as money laundering, exchange of stolen money, or claiming another's liquid assets through credit-card theft.

\section{B. Cons}

Although the ongoing commercialization of bodymodifying devices are creating a picture of complete ease, security, and ability to alleviate fear, there are mounting concerns. For example, scholars predict that threats of cyber viruses and worms may counteract hyper-marketing in institutions such as hospitals. While incentives for body-tech integration include: security, convenience, improved wellness, and are now being promoted through repeated media coverage and commercialization of such products, this type of marketing saturation has the potential to cause protestors-those who critically refuse adoption to be viewed as promoters of deviant activity, crime, or supporters of social inequalities, such as deficient health care [19]. Likewise, let us ponder on the momentum gathered by companies like Applied Digital Solutions, then the VeriChip and PositiveID, on the nation-wide attempt to enlist hospitals to chip patients with the VeriChip RFID transponder [20]. If this were to transpire through an unprecedented sweep, without any form of public resistance, could this then not lead to such technologies being identified as mandatory for high risk patients? In this risk-based society, it would not be far-fetched to expect a Medtronic device in every single person [21].

Once society accepts the fusion of human and machine there will be little hope of turning back time prior to this post-modern ideological shift. Once technology is viewed as a post-modern savior, opportunity to argue for freedom of choice, let alone a right to exercise resistance could very well seem absurd. At the point-in-time that former infrastructures are obsolete, industry will possess the greatest decisionmaking power in deciding what new innovation are to replace the former, with funding considerations often void of a thorough ethical investigation. This means humans are enslaved to a lifetime of upgrades that have as their underlying function, control [22]. If remote wireless technologies replace former infrastructures and become the inescapable trend for the future, there are various implications to consider. Although, the notion of wireless devices altering the human body on a bio-cellular level remain an unresolved debate, additional attention must be placed on the potential for harm to the human psyche, not necessarily due to a synoptic-centralization, but rather due to technological-constancy [7].

An additional concern is that an over emphasis on a technological society has the potential to evoke "over policing" of the system, with ever increased human rationale forcing the individual to either adopt or lose one's social net and thereby restrict one's ability to be a functional member 
in society [23]. One clear illustration of this is with America's current push to go cashless. Although this would provide a way to monitor money spent in the economy, and overthrow the possibility of money-laundering, it is not without its implications. One has only to follow the innovation process sequentially in order to elucidate where it could lead. For example, if the physical cash currency was to be removed and all transactional interchange was to rely on a wireless infrastructure, this would enact a soft-coercion of wireless payment scheme adoption, as refusal would prohibit the individual from functioning in commerce. If this were to transpire and the government did not place limits on the industry's need for continual disruption (by way of state regulation), it has the potential to usher in a complete reliance on industry. As innovations continue to progress and industry continues to lead the way in greater technological complexity-paving the way with mass media for massive consumer markets, skin-embedded products such as, transactional-based devices, could quickly swallow up present mechanisms, such as the use of banking debit and credit cards, as the initial costs of implementation can be argued to be far less than the costs associated with policing the system for theft-identity, money-laundering, stolen credit cards or passports, robberies as well as physical assaults [24].

\section{DISCUSSION}

\section{A. Marketing and Promotion Strategies}

According to William Herbert, companies and individuals within the United States particularly are aggressively promoting implant products for humans. He writes [15], p. 437:

In addition to utilizing hospitals and medical professionals as promoters, the product is being marketed for both security and recreational purposes. RFID implants are being publicized as a mere technological extension to the body-piercing trend that permits bodily integration with computers. A technology entrepreneur who volunteered for implants in both hands admitted to the New York Times that "the symbolism of the tag is much more of a big deal as a social marker." A website has been established in an effort to expand this social phenomenon of voluntary technological branding.

In addition large stakeholders, who have a strong economic interest in seeing the advancement of such technology, have volunteered to receive implants and have publicized their participation as part of a marketing strategy to promote commercialization of such products [25].

\section{B. Imbalance of Powers}

Considering the state of the global economy and the need to cut-costs in hopes of stabilizing its fragility, the push towards efficiency over quality is often being seen as the viable choice. It can be argued that such promotion of technology over consideration of choice is inadvertently shifting the balance of powers into the hands of the producing class-being industry. If we are not careful, this could lead to a form of organizational control, resulting once again in a restriction to humanity's fundamental rights to choose, as the consumer is not the worker, the patient, the prisoner, the military personnel or the actual adopters, but rather it is the corporations providing employment, the hospitals aiding the ill, the correctional facility housing the prisoner, the military base wielding the will of the solider, the supermarkets limiting the transactional method to its consumers, with multinationals leading the way.

Once the balance of powers are placed in the hands of industry to lead the way in innovation they have full control to usher in what new product to market to the consumer, while it is the individual user who becomes imprisoned to the technology being selected on their behalf, as they are unable to survive without the goods and services such adoption guarantees [26]. It is here that the buyer becomes the main marketable consumer and the user becomes subservient to the chosen system through a top-down implementation, in order that the individual may be able to have basic needs met in order to survive, let alone progress.

\section{Protecting Human Rights to Self-Govern}

Without true public forums for dialogue, debate and exchange, democratic nations have the potential to quickly erode. With the voice of the individuals being suppressed, industry would then be the most power stakeholder. Such an imbalance of power puts citizens at greater risk of being softly-coerced in one specific direction. With no means to exercise one's voice in an appropriate external forum, it becomes an "adapt or die" [27] kind of world. The detriment of the suppressed voice becomes two-fold. It can be argued to inadvertently force the individual's gaze to turn inward, looking to one's own human capital (physical body) as the final means of expression, or even worse it has the potential to break the human will in one's quest for individual freedom, whereby leaving the individual docile in the fight against the doctrine of inclusion that is more and more restricting meaningful discourse beyond the system's predefined parameters. It could be considered paralysis to a degree. Long-time proponents of RFID transponders describe this sentiment as "irrational paranoia by the vocal minority" [25].

Within a Democratic state it is essential that the system protects the people collectively, as well as individually. As such, it must seek to protect those individuals who wish to remain more egalitarian in life-style with de-centralized governing powers, in order that they may too, live in community, function in commerce and progress towards self-actualization without, for example, the mandatory adoption of bio-devices. And because we cannot have one without the other, this research also inadvertently defends those who wish to keep pace with the industry's steep innovation curve in so much that they decide to alter, change or modify one's own human body with the aid of technology-arguing alongside of other researchers-the human body is in fact one's own human capital [citation]. Certainly this does not endorse physical abuse, mutilation or suicide, but certainly leaves the right of bodycommercializing up to the individual, as one deems fit. This 
is a stance taken by Amal Graafstra of DangerThings.com [12].

The imbalance of powers [citation: Goffman] with the government and industry in conjunction to the lack of public forums available for the individual to express one's viewsexcluding various social cyber forums- raises additional ethical issues, such as, are these restrictions inadvertently promoting a turning inward to the human body as a form of silent communication. Likewise, could the push towards accepting a biotech-based society be promoting technology addictions and propel this excessive consumption to alter one's human body? If so, is it ethical to continue fueling and promoting an already existing consumerist mentality that is growing more and more reliant on the human body as a medium to convey one's message. It is here that we enter the slippery slope. And so can we see as how through "othering" [3], we put humanity at risk of having these rights taken away?

\section{CONCLUSION}

This article concerns itself with the individual turning inward to the remaking of the human body as a silent medium of communication. It can be argued that as the need for possession of capital is maximized, and this market is fully tapped with the banks largely owning our homes, cars and government owning our land, the individual is turning from outward commodities towards displaying ownership over oneself. As such individuals are more readily adopting the practices of a chosen sub-culture as being societal norms and mainstream practice. This influence, in conjunction to subdermal technologies being made accessible, along with a marginalization of the political voice, are inadvertently promoting the human gaze to move inward, whereby softlycoercing the individual to turn to one's own body as a vehicle for human expression as a means of displaying their rights of governance [15]. While this article supports the individual's current rights to self-govern body modifications through the use of technology, as well as supports the individual's right of refusal, it also suggests that extreme body-altering practices are putting humanity at risk of having these rights taken away.

The question then becomes fundamental, would we have this same human openness to remake the human-body through the aid of technology if it were no longer our decision to make? If it were being decided for us, rather than being a matter of one's own human expression and freedom of choice would early bio-tech adopters and body-modifiers possess the same propensity towards altering our human identity if by their very practices they were deemed as paving the way for a top-down implementation, weakening the individual's right of self-determination.

\section{REFERENCES}

K. Michael and M. G. Michael, "Historical Lessons on ID Technology and the Consequences of an Unchecked Trajectory," Prometheus, vol. 24, pp. 365-377, 2006. C. Lineberry. (2007). Tattoos: The Ancient and Mysterious History. http://www.smithsonianmag.com/history/tattoos144038580/?no-ist

[3] C. Malacrida and J. Low, Sociology of the Body: A Reader. Don Mills, Ontario: Oxford University Press, 2008.

[4] C. Shilling, "The Body in Sociology," in Sociology of the Body: A Reader, C. Malacrida and J. Low, Eds., ed Don Mills, Ontario: Oxford University Press, 2008, p. 305.

[5] C. Klesse, "'Modern Primitivism': Non-mainstream Body Modification and Racialized Representation," in Sociology of the Body: A Reader, C. Malacrida and J. Low, Eds., ed Don Mills, Ontario: Oxford University Press, 2008, p. 305.

[6] K. Michael and M. G. Michael, "Towards chipification: the multifunctional body art of the Net Generation," in Cultural Attitudes Towards Technology and Communication, Tartu, Estonia, 2006, pp. 622-641.

[7] J. van den Hoven and P. E. Vermaas, "Nano-Technology and Privacy: On Continuous Surveillance Outside the Panopticon," Journal of Medicine \& Philosophy, vol. 32, pp. 283-297, 2007.

[8] A. Masters and K. Michael, "Lend me your arms: The use and implications of humancentric RFID," Electronic Commerce Research and Applications, vol. 6, pp. 29-39, 2007.

[9] F. M. A. E. Report. (2007, 27 July 2007). VeriChip Corporation VeriMed Patient Identificator VeriChip Implant. Available: http://www.accessdata.fda.gov/scripts/cdrh/cfdocs/cfMAUDE/D etail.CFM?MDRFOI_ID=962453

[10] K. Michael and M. G. Michael, "The diffusion of RFID implants for access control and epayments: a case study on Baja Beach Club in Barcelona," in IEEE Symposium on Technology and Society, Wollongong, NSW, 2010, pp. 242-252.

[11] K. R. Foster and J. Jaeger, "RFID inside - The murky ethics of implanted chips," vol. 44, pp. 24-29, 2007.

[12] A. Graafstra, et al., "Social-technical issues facing the humancentric RFID implantee sub-culture through the eyes of Amal Graafstra," in IEEE International Symposium on Technology and Society, Wollongong, Australia, 2010, pp. 498 516.

[13] A. Light, "The Panopticon reaches within: how digital technology turns us inside out," vol. 3, pp. 583-598, 2010.

[14] C. Taylor, Hegel and Modern Society. Cambridge, United Kingdom: Cambridge University Press, 1979.

[15] W. A. Herbert, "No Direction Home: Will the Law Keep Pace With Human Tracking Technology to Protect Individual Privacy and Stop Geoslavery," Law and Policy for the Information Society, vol. 2, p. 436, 2006.

[16] C. M. Klugman, "From Cyborg Fiction to Medical Reality," Literature and Medicine, vol. 20, pp. 39-54, 2001.

[17] M. C. O'Connor. (2006). Insurer Running VeriChip Trial. Available: http://www.rfidjournal.com/articles/view?2496

[18] (2010). Tri-Council Policy Statement: Ethical Conduct for Research Involving Humans. Available: http://www.ncehrcnerh.org/english/code 2/

[19] K. Albrecht and L. McIntyre, Spychips: How Major Corporations and Government Plan to Track Your Every Move with RFID. New York: Thomas Nelson Inc, 2005.

[20] K. Michael, et al., "Microchip implants for humans as unique identifiers: a case study on VeriChip," in Conference on Ethics, Technology, and Identity, Delft, The Netherlands, 2008, pp. 8184.

[21] E. Strickland, "Medtronic Wants to Implant Sensors in Everyone," IEEE Spectrum, 2014.

[22] A. Masters and K. Michael, "Humancentric applications of RFID implants: the usability contexts of control, convenience and care," in The Second IEEE International Workshop on Mobile Commerce and Services, Munich, Germany, 2005, pp. 32-41.

[23] K. Michael and M. G. Michael, "The social and behavioural implications of location-based services," Journal of Location Based Services, vol. 5, pp. 121-137, 2011.

[24] M. G. Michael and K. Michael, "Toward a state of uberveillance," IEEE Technology and Society Magazine, vol. 29, pp. 9-16, 2010. 
[25] K. Michael and M. G. Michael, "The future prospects of embedded microchips in humans as unique identifiers: the risks versus the rewards," Media Culture and Society, vol. 35, pp. 7886, 2013.

[26] K. Michael and M. G. Michael, "Someone(thing)" to Watch Over Me: Big Data = Big Issues," Canberra2014.

[27] F. Hoque, "Adapt Or Die: Your Business's Only Options In An Evolving Economy," FastCompany, 2014. 